\title{
Strategies and solutions to alleviate access block and overcrowding in emergency departments
}

\author{
Stewart SW Chan *, NK Cheung, Colin A Graham, Timothy H Rainer
}

\section{A B S T R A C T}

Objectives: Access block refers to the delay caused for patients in gaining access to in-patient beds after being admitted. It is almost always associated with emergency department overcrowding. This study aimed to identify evidence-based strategies that can be followed in emergency departments and hospital settings to alleviate the problem of access block and emergency department overcrowding; and to explore the applicability of these solutions in Hong Kong.

Data sources: A systematic literature review was performed by searching the following databases: CINAHL, Cochrane Database of Systematic Reviews, EMBASE, MEDLINE (OVID), NHS Evidence, Scopus, and PubMed.

Study selection: The search terms used were "emergency department, access block, overcrowding". The inclusion criteria were full-text articles, studies, economic evaluations, reviews, editorials, and commentaries. The exclusion criteria were studies not based in the emergency departments or hospitals, and abstracts.

Data extraction: Abstracts of identified papers were screened, and papers were selected if they contained facts, data, or scientific evidence related to interventions that aimed at improving outcome

This article was published on 19 Jun 2015 at www.hkmj.org. measures for emergency department overcrowding and/or access block. Papers identified were used to locate further references.

Data synthesis: All relevant scientific studies were evaluated for strengths and weaknesses using appraisal tools developed by the Critical Appraisal Skills Programme. We identified solutions broadly classified into the following categories: (1) strategies addressing emergency department overcrowding: co-locating primary care within the emergency department, and fast-track and emergency nurse practitioners; and (2) strategies addressing access block: holding units, early discharge and patient flow, and political action-management and resource priority.

Conclusion: Several evidence-based approaches have been identified from the literature and effective strategies to overcome the problem of access block and overcrowding of emergency departments may be formulated.

Hong Kong Med J 2015;21:345-52
DOI: 10.12809/hkmj144399
SSW Chan *, MSc, FHKAM (Emergency Medicine)
NK Cheung, MB, ChB, FHKAM (Emergency Medicine)
CA Graham, MD, FCEM
TH Rainer, MD, FIFEM

Emergency Department, Prince of Wales Hospital; Accident and Emergency Medicine Academic Unit, The Chinese University of Hong Kong, Shatin, Hong Kong

* Corresponding author: stewart_chan@hotmail.com

\section{Introduction}

In the past 20 years, access block and emergency department (ED) overcrowding have emerged and given rise to major problems, affecting the health care systems of developed countries, including those in the US, UK, and Australia. ${ }^{1-4}$ In Australia, the term 'access block' is defined as the situation where patients in EDs are unable to gain access to in-patient beds within 8 hours of presentation to the ED. ${ }^{4}$ In the UK, it is defined as 4 hours or more from arrival to admission, transfer, or discharge. ${ }^{3}$ Although ED overcrowding may be due to many factors other than access block-such as increased ED attendances, inappropriate use of ED services, or deficiencies in ED medical and nursing staffing levels or patternsaccess block is almost always associated with overcrowding, and significantly leads to poor quality of care outcomes. ${ }^{5}$ Numerous studies from the US, UK, Canada, and Australia have shown that access block causes ED overcrowding and affects quality of care. ${ }^{6-10}$ Bullard et $\mathrm{al}^{8}$ reported that admitted patients "boarding" in the ED (ie access block) was the number one advocacy issue for the Canadian Association of Emergency Physicians. Richardson ${ }^{9}$ conducted a survey from 83 EDs in Australia and concluded that overall, caring for patients waiting for beds represented $40 \%$ of the workload of ED staff in major hospitals. Apart from this, ED overcrowding affects the outcomes of admitted patients. Sun et $\mathrm{al}^{10}$ performed a retrospective cohort analysis of 995379 ED visits resulting in admissions in 187 acute care hospitals in California, US, and found that periods of ED overcrowding were associated with increased mortality, longer length of stay, and higher costs for admitted patients. 


\section{急症室病人滯留和過度擁擠的管理策略和 解決方案}

陳兆華、張乃光、簡家簾、譚偉恩

目的 : 急症室病人滯留是指需要住院的病人不能及時地從急症室分流 至相應專科病房的情況, 一般與急診室過度擁擠有關。本研究旨在研 究在急症室和醫院環境中能夠舒緩病人滞留問題和急症室過度擁擠的 循證策略, 並探討這些解決方案是否適用於香港。

資料來源：通過以下資料庫進行系統性文獻搜索：CINAHL Cochrane Database of Systematic Reviews \EMBASE、MEDLINE (OVID)、NHS Evidence、Scopus和PubMed。

研究選取：用以搜索文獻的關鍵詞為「急症科, 滞留, 過度擁擠」 （emergency department, access block, overcrowding）。全文文章、 研究報告、經濟評價、綜述、社論和評論均被納入研究範圍。只有摘 要的研究, 以及那些並非建基於急症室或醫院的研究不被採納。

資料提取：按着揀選文章內的摘要進行篩選, 有關舒緩急症室病人滞 留和過度擁擠的措施的描述、數據或科學證據的文章均會被採納。本 研究也透過互聯網搜尋揀選文章內的參考文獻。

資料綜合：使用嚴格評價技能項目（Critical Appraisal Skills Programme）評估所有相關的科學研究的優點和弱點。我們把解決方 案大致分為以下兩項：（1）針對急症室過度擁擠的策略：在急症室 內同時設立基層醫療服務, 有快速程序及急症專科護士；（2）針對 急診室病人滯留問題的策略：設立觀察病房、提早讓病人出院和控制 病人流量, 以及採取政治行動, 即行政和資源優先權。

結論：按揀選文章中尋找到一些循證策略, 從中可制定一些能夠舒緩 急症室病人滞留和過度擁擠的措施。
Access block and ED overcrowding are detrimental to the morale of ED staff members. ${ }^{11}$ Moreover, a survey of 400 admitted ED patients by Bartlett and Fatovich ${ }^{12}$ in Perth, Australia reported that patients preferred waiting in ward corridors for a ward bed if there were no ED cubicles available. This study alone showed that access block, independent of overcrowding, affects patients. Jelinek et $\mathrm{al}^{13}$ also showed that overcrowding in the ED affects the supervision of junior doctors.

Overcrowding and access block in EDs are rapidly becoming problematic areas for the health system even in Hong Kong. Figure 1 shows a photograph depicting the crowded ED with literally dozens of patients waiting for admission, which is almost an everyday scenario in a major teaching hospital in Hong Kong. At the time of drafting of this manuscript, the hospital management had set a target that patients waiting for admission should not have to wait longer than 24 hours (Fig 2), a target that is ludicrous by international standards. This review therefore aimed to answer the question: what are evidence-based strategies and solutions that can be applied within the ED and the hospital setting that are

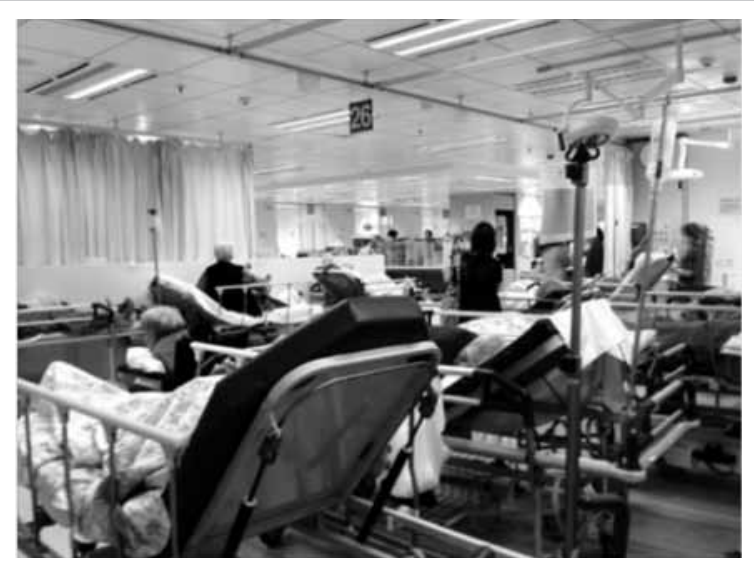

FIG I. Emergency department overcrowding from access block in Hong Kong

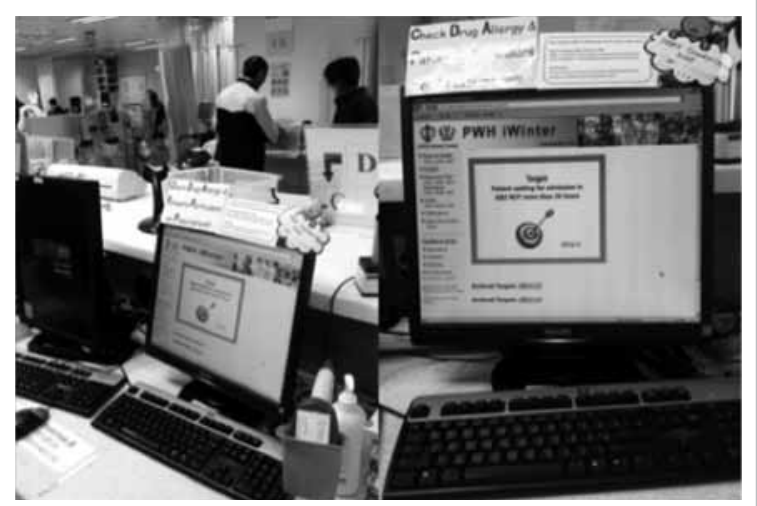

FIG 2. Hospital management target for access block, as displayed in the intranet portal for communication to all staff: patients should not have to wait in the emergency department for admission for longer than 24 hours

shown to be effective in alleviating ED overcrowding and access block? Further, we explored the relevance and applicability of these solutions identified with respect to the Hong Kong setting.

\section{Methods}

A search for English language papers was performed on the following electronic databases: CINAHL, Cochrane Database of Systematic Reviews, EMBASE, MEDLINE (OVID), NHS Evidence, Scopus, and PubMed. The search terms used were: "emergency department, access block, overcrowding". The inclusion criteria were: full-text articles, randomised controlled trials, systematic reviews, cohort studies, case-control studies, qualitative studies, economic evaluations, narrative reviews, editorials, and commentaries. The exclusion criteria were studies with interventions that were not primarily based in 
the ED or hospital (eg primary care or pre-hospital strategies) and abstracts.

Abstracts of identified papers were screened, and papers were selected if they contained facts, data, or scientific evidence related to interventions that aimed at improving outcome measures for ED overcrowding and/or access block. References identified from these articles were used to locate further references. All relevant scientific studies were evaluated for strengths and weaknesses by using appraisal tools developed by the Critical Appraisal Skills Programme, which can be accessed through the link: <http://www.casp-uk.net/>.

\section{Results}

The number of citations returned from the search was as follows: CINAHL (11), Cochrane Database of Systematic Reviews (0), EMBASE (39), MEDLINE (OVID) [11], NHS Evidence (166), Scopus (32), and PubMed (20). These citations were screened for relevance and fulfilment of inclusion and exclusion criteria. A total of 22 papers were selected which included one systematic review, 12 cohort studies, seven reviews, one qualitative study, and one expert opinion article. From these article references, more papers that were relevant to the subject were found and studied.

The review identified numerous management interventions that were likely to be effective in improving outcome measures to prevent ED overcrowding and access block. They are organised and listed below:

(1) Strategies primarily addressing ED overcrowding:

(a) Co-locating primary care within the ED; and

(b) Fast-track and emergency nurse practitioners (ENPs).

(2) Strategies primarily addressing access block:

(a) Holding units;

(b) Early discharge and patient flow; and

(c) Political action-management and resource priority.

\section{Discussion}

Strategies primarily addressing overcrowding in emergency departments

\section{Co-locating primary care within the emergency departments}

Overcrowding of ED has been attributed to primary care attenders inappropriately utilising the ED. ${ }^{14,15}$ If this were true, then the provision for additional number of primary care practitioners to the ED physician workforce would follow as a possible logical solution to counter ED overcrowding.

There is a wide variation in the incidence of primary care attendance in the ED, with figures ranging from $6 \%$ to $60 \%$ among hospitals in the UK. ${ }^{16}$ Variations in these studies may be due to differences in concept as to what primary care problems need or need not be treated in the ED. ${ }^{17}$ It was shown that expanding primary care and out-of-hour services may lead to decreased primary care attendance at EDs. ${ }^{18}$ A considerable proportion of patients attending the ED could be adequately looked after by general practitioners (GPs) or primary care physicians. Although it is considered cost-effective, one study did find that GPs tend to utilise more resources and another study showed that providing primary care services in the ED actually increased the number of primary care attendances, resulting in increased waiting time. ${ }^{19-21}$

The synthesis of all these studies suggests that co-locating primary care within the ED is a workable solution in most instances, but the extent of the benefits will depend on the relative importance of primary care attendance as a cause for overcrowding, which differs from country to country and from one hospital to another. In Hong Kong, the principle behind this solution has already been applied in several hospitals, but is yet to be developed into a territory-wide systematic strategy. In the past several years, some hospitals have started to employ parttime GPs to provide regular session-based services in the ED. Their duty is to handle cases of low acuity and this has considerably helped in reducing congestion at EDs. Although there have not been any published data to show that these arrangements improve waiting times in Hong Kong, our experience is that these locum doctors do alleviate overcrowding whenever they are present. In our hospital's ED, the GPs are encouraged to discuss difficult cases with senior doctors in the EDs, who would advise on treatment or disposition, or even take over the patient for further management. In this way, quality of care can be ensured. This approach seems to be promising and a model that can be improved and developed further. Based on the cited evidence, this may have implications beyond just solving the manpower number issue unto a more comprehensive strategy and direction in health care planning.

\section{Fast-track and emergency nurse practitioners}

The concept of fast-track service stems from the fact that most of the crowding in an ED may actually involve low acuity patients like those with minor injuries or minor illnesses. Therefore, fast-track services for such patients may be an important front-end operational strategy to relieve congestion. If the fast-track services are efficiently designed and provided by dedicated staff at a designated area in the ED, we can expect improvement in flow and elimination of wastes, which may result in shorter overall waiting times. A review by Yoon et $\mathrm{al}^{22}$ commissioned by the Canadian Health 
Technology Assessment, concluded that fast-track systems in EDs are efficient, cost-effective, safe, and satisfactory for patients. Since 2002, the UK National Health Service (NHS) has also encouraged the national use of fast-track systems under the 'see and treat' principle. ${ }^{3}$ The introduction of fast-track systems has been investigated in a wide variety of clinical settings. ${ }^{23-26}$ These studies found that fasttrack systems decreased patient waiting times and shortened the overall length of stay in EDs. The rate of patients "left without being seen" was also reduced. Further, quality of care was not compromised, as shown by data on patient satisfaction, unscheduled reattendance, and mortality rates. A key principle of using fast-track systems is to have experienced and competent staff designated to 'see and treat' the patients.

Studies also suggest that having ENPs incorporated into these systems for seeing and treating front-end strategies may further increase efficiency in relieving overcrowding. Emergency nurse practitioners have been increasingly used in EDs in the UK since the 1990s. ${ }^{27}$ Carter and Chochinov ${ }^{28}$ performed a systematic review of ENPs working in the ED by looking at the key outcome measures of waiting times, patient satisfaction, quality of care, and cost-effectiveness. They found that ENPs can reduce waits, lead to high patient satisfaction, and provide quality of care equivalent to a mid-grade resident doctor, although the costs of resident doctors are higher. A recent Australian study which included ENPs and physicians working in an ED fast-track unit of a tertiary hospital showed that while the quality of care was high in both groups, patient satisfaction score was significantly higher with the ENP group than with the physician group. ${ }^{29}$

In Hong Kong, formal training of ENPs has been developed only recently. This started when two experienced emergency nurses from the authors' institution were funded by a charitable foundation to receive ENP training in the UK in 2006. They subsequently started their ENP practice in June 2007 with a scope of practice focusing primarily on minor injuries. In 2010, a university master's programme for advanced ENPs was first established in Hong Kong to provide education and training for emergency nurses. Currently in our ED, ENPs are on roster for 5 days a week to 'see and treat' patients, numbering up to 20 patients per 8-hour shift, with holistic responsibilities which include performing minor procedures such as suturing in conjunction with a vast array of nursing care services for the patients they have seen. A retrospective study from our department reported that ENP services reduced waiting time and processing time without compromising quality of care. ${ }^{30}$ The future training and development of more ENPs into the workforce, and their incorporation into an ED fast-track service, are promising strategies for alleviating ED overcrowding in Hong Kong.

Nevertheless, there are certain issues that are still stumbling blocks. Currently, nurses in Hong Kong are not legally allowed to prescribe medications and issue sick leave certificates. Therefore, ENPs are not completely independent although they carry a good amount of clinical load. The ENPs also need autonomy to refer patients for X-rays and allied health services (eg physiotherapy) and these are important barriers for effective development of their service. Finally, there is a debate as to how costeffective it is to designate an ENP (at least at the grade of Advanced Practising Nurse) to perform duties that can be performed by a junior resident doctor. The answer to this question will depend very much on the relative supply of each of these categories of staff prevailing at that point of time.

\section{Strategies primarily addressing access block}

The possible causes of access block include (1) the disinclination for clinicians to discharge patients, (2) inefficient flow in the discharge process, and (3) genuinely insufficient bed capacity. These causes of access block are discussed further and addressed under the following three possible solutions.

\section{Holding units}

Holding units are clinical decision units or observation units within the ED. In the US, reviews by the Institute of Medicine Committee found that such units were able to reduce the need for boarding or ambulance diversion, which means these were able to alleviate access block and ED overcrowding. ${ }^{31}$ They also contribute to reduction in hospitalisation and improvements in ambulatory care. In 2007, 1746 EDs in the US reported having observation units and this constituted about $36 \%$ of the total number of EDs. ${ }^{32}$ Among them, $56 \%$ were administratively managed by ED staff. In the UK, Cooke et $\mathrm{al}^{3}$ also reviewed the use of observation units and found that they might reduce length of stay in the ED and possibly in the hospital too. Nevertheless, the review concluded that results of the studies were variable and confounded by methodological issues. Experience in an ED in Spain in 2009 showed that opening of a 16-bed holding unit in the ED of a 900-bed teaching hospital led to improvement in access block. ${ }^{33}$ Observation units have also been shown to play a role in selected clinical conditions, like acute exacerbation of heart failure, which is known to be a very common cause for hospital admission. ${ }^{34}$ Another condition in which observation units can be helpful is acute pyelonephritis. ${ }^{35} \mathrm{~A}$ retrospective cohort study was performed reviewing 633 patients with pyelonephritis before and after the opening of the observation unit. The proportion of 
patients admitted to hospital from the ED decreased significantly from $36 \%$ to $26 \%$ after the opening of the observation unit. ${ }^{35}$

The functions and setup of these holding units may differ from one institution to another. If the setup is more like a short-stay ward or even an in-patient ward, then its favourable effect on access block may be attributed simply and chiefly from an increase in the number of beds, as opposed to the streamlining of management. In Hong Kong, the idea of an ED observation unit is not new and many EDs, including ours, have been running observation units for the past 15 to 20 years. The difference is that, over the past 3 to 4 years, many observation units have been expanded with increased number of beds and broader case-mix, and renamed as 'Emergency Medicine Wards'. For example, in our ED, the 20-bed observation unit was expanded to a 40-bed Emergency Medicine Ward with introduction of formal care protocols and pathways for managing conditions such as congestive heart failure, chronic obstructive airway diseases, deep venous thrombosis, cellulitis, and pyelonephritis. From our experience, we are skeptical if the Emergency Medicine Ward has contributed significantly in alleviating access block or ED overcrowding. This ward has provided extra beds and obviously alleviated some of the bed access problems. Therefore, it just means that the duty and workload are shifted to the ED with a cost involved, which includes space and human resources at the minimum. Within the holding unit context, further contributions over and above this would require adherence to management protocols that have been proven to safely reduce length of stay or hospitalisation rates.

In Canada, Schull et $\mathrm{al}^{36}$ retrospectively evaluated the effect of ED clinical decision units on overall ED patient flow, comparing outcomes (including length of stay, admission rate, etc) between seven EDs which had implemented clinical decision units and nine control EDs without clinical decision units. They concluded that the benefits of clinical decision units were just marginal and that the potentials for gains in efficiency were limited.

In summary, there is some evidence for the role of holding units for alleviating access block and overcrowding but this needs to be incorporated together with carefully planned clinical management protocols and adequate support staff.

\section{Early discharge and patient flow}

In a recent study based on ED presentations, inpatient admission, and discharge data from 23 hospitals in Queensland, Australia, it was shown that during the days when 'discharge peak' lags behind the peak in in-patient admissions, hospitals exhibit increased levels of occupancy, in-patient and ED length of stay, and increased access block. ${ }^{37,38}$
Initiatives directed at early in-patient discharges would effectively mitigate the problem of ED overcrowding and access block.

Since access block increases the clinical risk of patients who might be deprived of timely attention, assessment and management by various specialty medical teams, considering earlier discharge of lowrisk, almost fully recovered in-patients in order to create bed capacity for the incoming sick patients would be an important principle worth putting into practice, and for clinicians and managers to balance the risks and benefits. This involves researching and refining prediction rules to categorise the levels of risk of discharging in-patients earlier. ${ }^{2,39}$ This process is described as 'reverse triage', and described by Kelen et $\mathrm{al}^{39}$ as to select patients who can be discharged safely with little risk of serious consequence, in the event of disasters that demand increased hospital bed capacity. In 2012, an anecdotal report was published describing how this reverse triage system was put to effective use in an unexpected event resulting in a sudden demand for beds. ${ }^{40}$ Although initially described for use during disasters, this system is also considered suitable even for everyday hospital use to ensure safe management of hospital capacity or to reduce access block. ${ }^{2,39}$

There is some evidence from a systematic review of nine studies which showed that involving social workers to support discharge of elderly patients was able to reduce the readmission rate within 6 to 12 months without apparent increase in mortality. However, the effect on length of hospital stay was uncertain. ${ }^{41}$ Expanding social work services may help to prevent re-attendance, overcrowding, and access block.

Discharge lounges are areas in the hospital for patients to wait until transport and other administrative discharge arrangements are completed. A study found that after the introduction of such lounges, there can be substantial savings in bed hours (early discharge and reduced length of stay). ${ }^{42}$ However, further studies focusing more on economic evaluations are needed. In hospital wards, delay in discharges may also be associated with attitudes of staff members who think that quicker discharges would result in more admissions, and hence increased workload. Incentives and reward programmes to motivate in-patient staff members to speed up the discharge process are therefore important.

Some studies have shown that modelling methods using patient flow systems or bed management techniques may improve the flow of patients by identifying bottlenecks and key factors driving access block. For example, Martin et $\mathrm{al}^{43}$ found that the greatest source of delay in patient flow was the waiting time from an admission request for bed to the actual time of exit from the ED for 
admission. Some researchers have developed a mathematical model using the ED census to predict crowding, daily surge and operational efficiency, the basic pattern of the ED census comprising input, throughput and output. ${ }^{44}$ King et $\mathrm{al}^{45}$ showed that through the application of "lean thinking" and by process mapping followed by identification of value streams in the ED, they were able to significantly improve waiting times and length of stay in EDs. Strategies can also be focused on addressing demand on in-patient beds by gathering predictable data on daily or weekly peaks and valleys, and be able to distribute admissions more smoothly and evenly across the weeks. ${ }^{2,46}$

\section{Political action-management and resource priority}

One logical and clear solution for managing access block is to increase bed capacity, increase the number of acute beds and corresponding staff strength in the hospitals. In reality, this is an issue of resource availability and prioritising, a problem which the hospital management constantly grapples with, in an attempt to find the best balance. Therefore, health care institutional funders need to be convinced that ED overcrowding and access block are issues of significant importance compared to other areas of health care, in which resource distribution is also needed. Ultimately, when all other solutions fail simply because the root cause of the problem is a system capacity matter, then effective responses need to come from the institutional and systemwide level to increase capacity. There are many avenues and methods by which the attention of the government and health authority can be drawn to help focus on increasing the number of acute hospital beds and thereby reducing access block. Health care professionals can press for changes by taking collective actions, organising information campaigns, lobbying, drawing attention of the press and media, negotiations, and even by public demonstrations.

The review by Moskop et $\mathrm{al}^{2}$ presented an anecdotal report of an information campaign conducted by doctors in Canada that effectively influenced changes in the government funding policies. ${ }^{47}$ In April 2005, emergency physicians at Vancouver General Hospital, frustrated by their ongoing failure to persuade hospital administration to address their access block crisis, gave selected patients a statement expressing their "nonconfidence in the ability of the Vancouver General Hospital ED to provide safe, timely, and appropriate emergency medical care." 47 Emergency physicians at other hospitals in Vancouver expressed similar concerns publicly. ${ }^{47}$ As a result of this campaign, the provincial Ministry of Health injected significant funding to address the problem during that period. ${ }^{47}$
In order to relieve access block, governments can also set targets and performance measures for hospitals and the most well known among them is the 4-hour rule introduced by the UK NHS in $2004 .{ }^{48}$ By this measure, $98 \%$ of ED patients are to be seen and either admitted, discharged, or transferred within 4 hours from the time of triage. This makes hospital administration take more responsibility for the problem of access block, which becomes a 'hospitalwide issue' rather than purely an ED problem. As a result, emergency care was prioritised, government funding was increased, facilities were upgraded, and more staff employed in order that hospital EDs can achieve the target. ${ }^{48}$ Before implementation of the 4-hour rule, as many as $23 \%$ of patients waited longer than 4 hours in the ED, but the 2007 statistics show that $97.7 \%$ patients were assessed, treated, and discharged within 4 hours. ${ }^{48,49}$ In 2009 in Perth, the Western Australian government also introduced a similar 4-hour rule for hospitals, whereby initially $85 \%$ and eventually $98 \%$ of patients presenting to the ED should be either discharged home or admitted into hospital within 4 hours. ${ }^{50}$ A study was performed by retrieving hospital and patient data which looked at outcome measures like mortality rates, access block, and overcrowding rates preand post-introduction of the 4-hour rule. ${ }^{50}$ It was found that reversal of overcrowding coincided with significant improvements in mortality rate in three tertiary hospitals in which the rule was introduced..$^{50}$ Although targets are intended to improve the quality of care, sometimes patient care can be compromised in order to meet stringent time targets, as seen with Mid Staffordshire NHS Trust in the UK which was reported to have neglected clinical needs and safety of patients in order to achieve time targets. ${ }^{48}$ In 2011, the 4-hour target in England was replaced by other clinical indicators.

\section{Limitations}

Due to differences in health systems, some of the solutions discussed in the Hong Kong perspective may be less practicable in other countries. For example, in some countries the number of primary care physicians from the public system available to participate in ED work may be limited; and the private practitioners may generally be less motivated to provide part-time services.

\section{Conclusion}

Several possible strategies and management approaches effective in dealing with the complex problem of access block and ED overcrowding in hospitals have been identified and discussed. Some of these solutions have been developed for many years and are supported by current evidence, while others are promising, warranting more detailed 
investigation. The strategy to co-locate primary care in the ED is worth evaluating more, the extent of the benefits being dependent on the relative predominance of 'primary care attendance' as a cause of ED overcrowding, and the availability of GPs or other primary care providers in the workforce. Further development of fast-track or minor injury units, the use of 'see and treat' strategies, and further training of more ENPs are also important directions to take. Holding units have been quite extensively studied and there is some evidence for their role, although these need to be incorporated together with well-planned management protocols and adequate staff support. 'Reverse triage' is a relatively new concept and needs to be well formulated. Prediction rules to select patients who can be discharged safely with little risk of serious consequences have been derived and can be used in the event of vast surges in demand for hospital bed capacity. This may be applicable for accelerating discharge of patients safely in times of access block.

\section{References}

1. Moskop JC, Sklar DP, Geiderman JM, Schears RM, Bookman KJ. Emergency department crowding, part 1concepts, causes, and moral consequences. Ann Emerg Med 2009;53:605-11.

2. Moskop JC, Sklar DP, Geiderman JM, Schears RM, Bookman KJ. Emergency department crowding, part 2barriers to reform and strategies to overcome them. Ann Emerg Med 2009;53:612-7.

3. Cooke M, Fisher J, Dale J, et al. Reducing attendances and waits in emergency departments. A systematic review of present innovations. London: The National Coordinating Centre for the Service Delivery and Organisation, London School of Hygiene and Tropical Medicine; 2004.

4. Forero R, McCarthy S, Hillman K. Access block and emergency department overcrowding. Available from: http://ccforum.com/content/15/2/216. Accessed 1 Feb 2013.

5. Dunn R. Reduced access block causes shorter emergency department waiting times: An historical control observational study. Emerg Med 2003;15:232-8.

6. Forero R, Hillman KM, McCarthy S, Fatovich DM, Joseph AP, Richardson DB. Access block and ED overcrowding. Emerg Med Australas 2010;22:119-35.

7. Gilligan P, Winder S, Ramphul N, O'Kelly P. The referral and complete evaluation time study. Eur J Emerg Med 2010;17:349-53.

8. Bullard MJ, Villa-Roel C, Bond K, Vester M, Holroyd B, Rowe B. Tracking emergency department overcrowding in a tertiary care academic institution. Healthc Q 2009;12:99106.

9. Richardson D. 2008 - 2. Access block point prevalence survey. The Australasian College for Emergency Medicine 2008. Available from: https://www.acem.org.au/ getattachment/e6442562-06f7-4629-b7f9-8102236c8b9d/ Access-Block-2009-point-prevalence-study.aspx. Accessed 1 Feb 2013.

10. Sun BC, Hsia RY, Weiss RE, et al. Effect of emergency department crowding on outcomes of admitted patients.
Ann Emerg Med 2013;61:605-11.e6

11. Kilcoyne M, Dowling M. Working in an overcrowded accident and emergency department: nurses' narratives. Aust J Adv Nurs 2007;25:21-7.

12. Bartlett S, Fatovich D. Emergency department patient preferences for waiting for a bed. Emerg Med Australas 2009;21:25-30.

13. Jelinek GA, Weiland TJ, Mackinlay C. Supervision and feedback for junior medical staff in Australian emergency departments: findings from the emergency medicine capacity assessment study. BMC Med Educ 2010;10:74.

14. Rajpar SF, Smith MA, Cooke MW. Study of choice between accident and emergency departments and general practice centres for out of hours primary care problems. J Accid Emerg Med 2000;17:18-21.

15. Bianco A, Pileggi C, Angelillo IF. Non-urgent visits to a hospital emergency department in Italy. Public Health 2003;117:250-5.

16. Murphy AW. 'Inappropriate' attenders at accident and emergency departments I: definition, incidence and reasons for attendance. Fam Pract 1998;15:23-32.

17. Gill JM, Reese CL 4th, Diamond JJ. Disagreement among health care professionals about the care needs of emergency department patients. Ann Emerg Med 1996;28:474-9.

18. Roberts E, Mays N. Accident and emergency care at the primary-secondary interface: a systematic review of the evidence on substitution. London: King's Fund Commission; 1997.

19. Dale J, Lang H, Roberts JA, Green J, Glucksman E. Cost effectiveness of treating primary care patients in accident and emergency: a comparison between general practitioners, senior house officers, and registrars. BMJ 1996;312:1340-4.

20. Gibney D, Murphy AW, Smith M, Bury G, Plunkett PK. Attitudes of Dublin accident and emergency department doctors and nurses towards the services offered by local general practitioners. J Accid Emerg Med 1995;12:262-5.

21. Krakau I, Hassler E. Provision for clinic patients in the ED produces more nonemergency visits. Am J Emerg Med 1999;17:18-20.

22. Yoon P, Steiner I, Reinhardt G. Analysis of factors influencing length of stay in the emergency department. CJEM 2003;5:155-61.

23. Sanchez M, Smally AJ, Grant RJ, Jacobs LM. Effects of a fast-track area on emergency department performance. J Emerg Med 2006;31:117-20.

24. Rodi SW, Grau MV, Orsini CM. Evaluation of a fast track unit: alignment of resources and demand results in improved satisfaction and decreased length of stay for emergency department patients. Qual Manag Health Care 2006;15:163-70.

25. O’Brien GM, Shapiro MJ, Woolard RW, O'Sullivan PS, Stein MD. "Inappropriate" emergency department use: a comparison of three methodologies for identification. Acad Emerg Med 1996;3:252-7.

26. Kwa P, Blake D. Fast track: has it changed patient care in the emergency department? Emerg Med Australas 2008;20:105.

27. Neades BL. Expanding the role of the nurse in the Accident and Emergency department. Postgrad Med J 1997;73:17-22.

28. Carter AJ, Chochinov AH. A systematic review of the impact of nurse practitioners on cost, quality of care, satisfaction and wait times in the emergency department. 
CJEM 2007;9:286-95.

29. Dinh M, Walker A, Parameswaran A, Enright N. Evaluating the quality of care delivered by an emergency department fast track unit with both nurse practitioners and doctors. Australas Emerg Nurs J 2012;15:188-94.

30. Chung J, Way R, Rainer TH. Development of an emergency nurse practitioner service in Hong Kong through international collaboration: evaluation of the service development. 1st Global Conference on Emergency and Trauma Care; 2014 Sep 18-21; Dublin, Ireland. Int Emerg Nurs 2014;22:237-60. Available from: http://www. internationalemergencynursing.com/article/S1755599X(14)00280-8/fulltext. Accessed 6 Nov 2014.

31. Institute of Medicine Committee on the Future of Emergency Care in the United States Health System. Hospital-based emergency care: At the Breaking Point (2007). Washington, DC: National Academies Press; 2006. Available from: http://www.nap.edu/catalog/11621.html. Accessed 15 Feb 2013.

32. Wiler JL, Ross MA, Ginde AA. National study of emergency department observation services. Acad Emerg Med 2011;18:959-65.

33. Gómez-Vaquero C, Soler AS, Pastor AJ, Mas JR, Rodriguez JJ, Virós XC. Efficacy of a holding unit to reduce access block and attendance pressure in the emergency department. Emerg Med J 2009;26:571-2.

34. Collins SP, Schauer DP, Gupta A, Brunner H, Storrow AB, Eckman MH. Cost-effectiveness analysis of ED decision making in patients with non-high-risk heart failure. Am J Emerg Med 2009;27:293-302.

35. Schrock JW, Reznikova S, Weller S. The effect of an observation unit on the rate of ED admission and discharge for pyelonephritis. Am J Emerg Med 2010;28:682-8.

36. Schull MJ, Vermeulen MJ, Stukel TA, et al. Evaluating the effect of clinical decision units on patient flow in seven Canadian emergency departments. Acad Emerg Med 2012;19:828-36.

37. Khana S, Boyle J, Good N, Lind J. Early discharge and its effect on ED length of stay and access block. In: Meader AJ, Matin-sanchez FJ, editors. Health informatics: building a healthcare future through trusted information. Amsterdam: IOS Press; 2012: 92-8.

38. Khana S, Boyle J, Good N, Lind J. Unravelling relationships: Hospital occupancy levels, discharge timing and emergency department access block. Emerg Med Australas 2012;24:510-7.

39. Kelen GD, Kraus CK, McCarthy ML, et al. Inpatient disposition classification for the creation of hospital surge capacity: a multiphase study. Lancet 2006;368:1984-90.

40. Satterthwaite PS, Atkinson CJ. Using 'reverse triage' to create hospital surge capacity: Royal Darwin Hospital's response to the Ashmore Reef disaster. Emerg Med J 2012;29:160-2.

41. Hyde CJ, Robert IE, Sinclair AJ. The effects of supporting discharge from hospital to home in older people. Age Ageing 2000;29:271-9.

42. Cowdell F, Lees B, Wade M. Discharge planning. Armchair fan. Health Serv J 2002;112:28-9.

43. Martin M, Champion R, Kinsman L, Masman K. Mapping patient flow in a regional Australian emergency department: a model driven approach. Int Emerg Nurs 2011;19:75-85.

44. Flottemesch TJ, Gordon BD, Jones SS. Advanced statistics: developing a formal model of emergency department census and defining operational efficiency. Acad Emerg Med 2007;14:799-809.

45. King DL, Ben-Tovim DI, Bassham J. Redesigning emergency department patient flows: application of Lean Thinking to health care. Emerg Med Australas 2006;18:391-7.

46. Litvak E, Buerhaus PI, Davidoff F, Long MC, McManus ML, Berwick DM. Managing unnecessary variability in patient demand to reduce nursing stress and improve patient safety. Jt Comm J Qual Patient Saf 2005;31:330-8.

47. Abu-Laban RB. The junkyard dogs find their teeth: addressing the crisis of admitted patients in Canadian emergency departments. CJEM 2006;8:388-91.

48. Letham K, Gray A. The four-hour target in the NHS emergency departments: a critical comment. Emergencias 2012;24:69-72.

49. Department of Health (UK). Hospital waiting times and waiting lists. 2010. Available from: http://webarchive. nationalarchives.gov.uk/20100406182906/http:/www.dh.gov.uk/en/ Publicationsandstatistics/Statistics/Performancedataandstatistics/ HospitalWaitingTimesandListStatistics/index.htm. Accessed 1 Mar 2013

50. Geelhoed GC, de Klerk NH. Emergency department overcrowding, mortality and the 4-hour rule in Western Australia. Med J Aust 2012;196:122-6. 